\title{
FMTVDM/BEST Imaging Equally Applicable for Male Breast Cancer
}

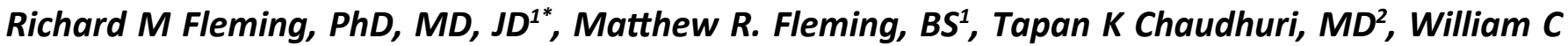 \\ Dooley, MD ${ }^{3}$ and Andrew McKusick, BS Pharm ${ }^{1,4}$
}

${ }^{1}$ FHHI-Omnificlmaging-Camelot, Los Angeles, CA, USA

${ }^{2}$ Eastern Virginia Medical School, USA

${ }^{3}$ Oklahoma University Health Science Center, USA

${ }^{4}$ Sebec Consulting \& Media, USA

*Corresponding author: Richard M Fleming, PhD, MD, JD, FHHI-Omnific Imaging-Camelot, Los Angeles, CA, USA

\section{Keywords}

FMTVDM/BEST Imaging@®, Breast Cancer, Breast Inflammation, Quantification, Al, Nuclear Camera Quantitative Calibration, Patent protected, Male Breast Cancer

Prior to FMTVDM/BEST Imaging, diagnostic testing was limited to looking for breast cancer either using "qualitative" imaging defining disease as either present or absent, or semiquantitative methods [1-10] which is also limited to the same yes you have breast cancer or no you don't interpretation. These imaging methods include mammography, ultrasound, CT, MRI, as well as other SPECT/Planar and PET imaging approaches and as such are associated with sensitivity and specificity problems. These tests are further limited when imaging dense breast tissue or when breast implants exist either for augmentation, following mastectomy or when looking for breast cancer in men.

The ability of FMTVDM/BEST to differentiate transitional changes in tissue, associated with regional blood flow differences (RBFDs) and increasing tissue metabolism, makes it possible for FMTVDM/BEST to measure these tissue changes across an entire spectrum of changes; recognizing a "Health-Spectrum" shown by Figure 1.

The interaction between cellular genetics and environmental factors consequently influence changes in tissue resulting in transitional changes including regional blood flow differences and metabolism. At one end of the spectrum is the absence of life, which may or may not be associated with a significant accumulation of cellular debris, inter alia, calcium, which may occur prior to the actual loss of cellular "life". In order of increasing regional blood flow and cellular metabolism are what is considered to be the "normal" state of a given tissue; resulting changes occurring due to an increased signaling and consequential accumulation of an inflammatory state; sequentially followed by further changes in tissue transitioning through increasingly metabolically active tissue with increased metabolic activity and demands for increased regional blood flow, until arriving at a tissue state where the expected controls and functionality of tissue no longer exist; what has classically been defined as "cancer". Implicit in this understanding is the appreciation that this continuum across transitional states reflects the interrelationship between these various "Health-Spectrum" states, which (1) Are not defined by some arbitrary absolute cutoffs between tissue states, (2) Demonstrate the ability of tissues to transition in either direction towards "normalization" or towards "cancer" and (3) Allow for the absolute measurement of the effect of treatment upon any of these tissue states across the "HealthSpectrum" providing the ability to direct care at the "patient-specific" level, improving outcomes across

Citation: Fleming RM, Fleming MR, Chaudhuri TK, Dooley WC, Mc Kusick A (2019) FMTVDM/BEST Imaging Equally Applicable for Male Breast Cancer. Int J Womens Health Wellness 5:093. doi. org/10.23937/2474-1353/1510093

Accepted: April 08, 2019: Published: April 10, 2019

Copyright: (c) 2019 Fleming RM, et al. This is an open-access article distributed under the terms of the Creative Commons Attribution License, which permits unrestricted use, distribution, and reproduction in any medium, provided the original author and source are credited. 
Measuring changes in breast tissue as it changes from normal to cancer.
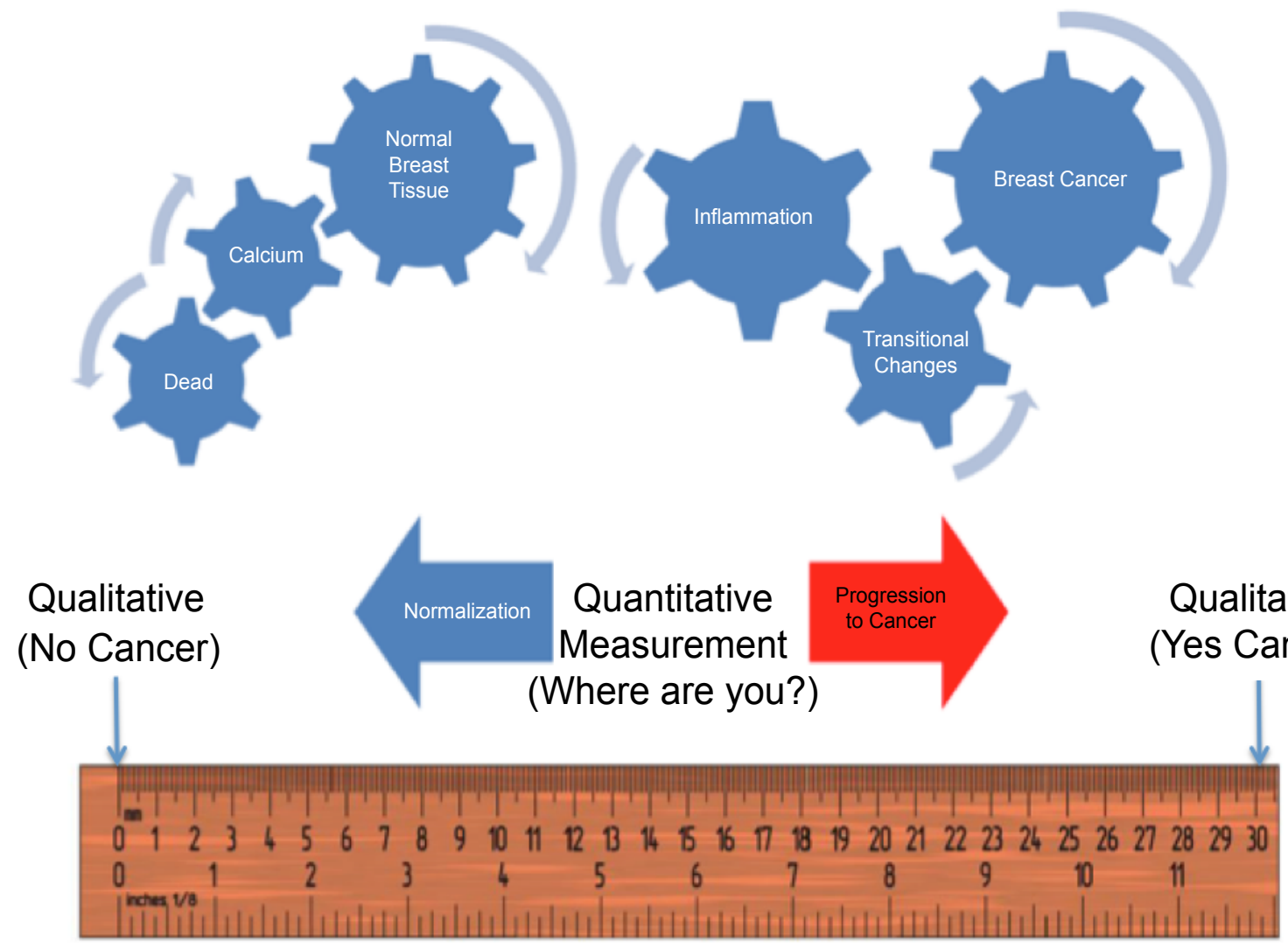

Figure 1: FMTVDM/BEST "Health-Spectrum” Measurements.

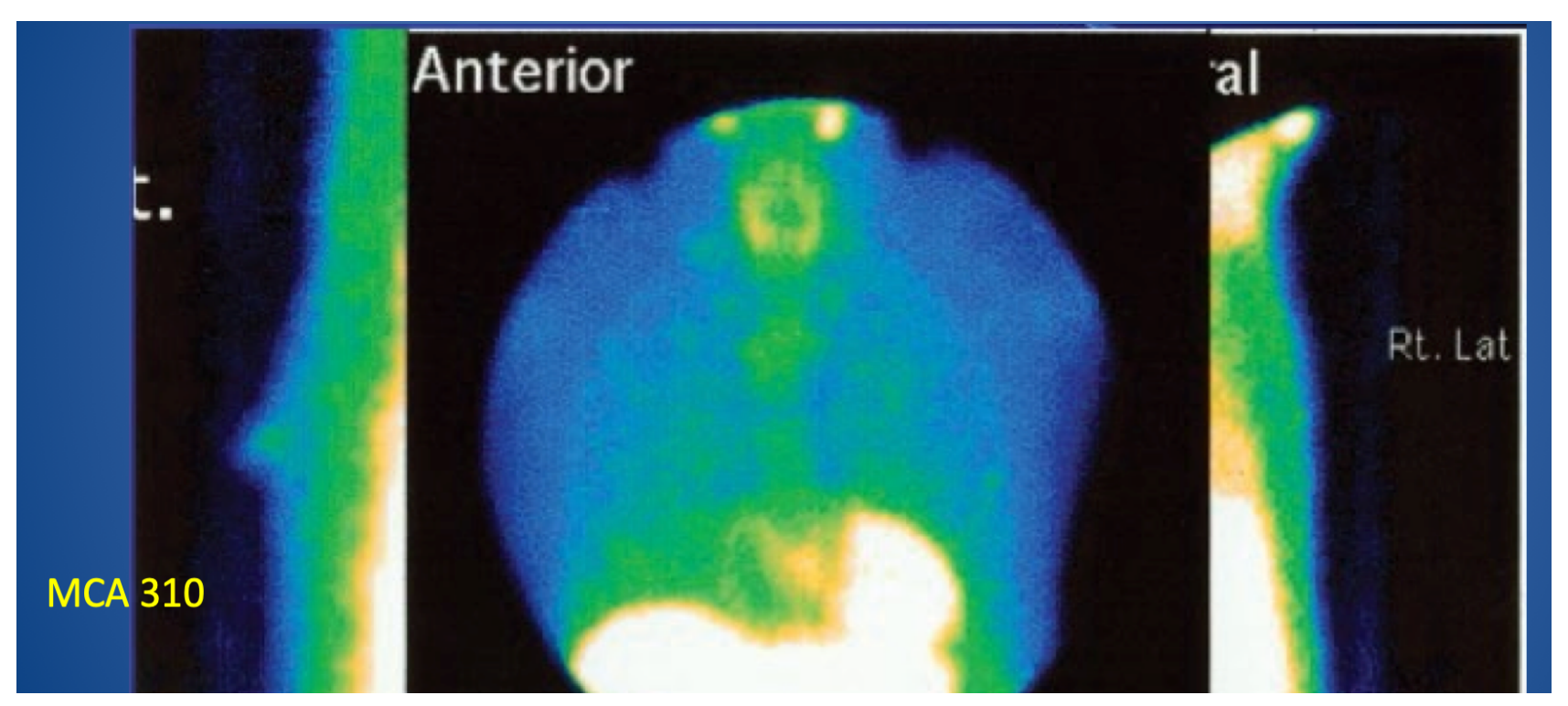

Figure 2: FMTVDM/BEST Imaging of a male patient.

these transitional states; saving time, money and most importantly lives.

Because FMTVDM/BEST measures the RBFDs and metabolism of tissue and does not require tissue to compress for imaging and measurement, FMTVDM/BEST can be used to evaluate breast cancer in men as well as women. The following study represents a man referred for evaluation of a breast lump using FMTVDM/BEST.

\section{FMTVDM/BEST Imaging of Male Patient}

A wife discovered a lump in the breast of her husband on Valentine's Day. There was no family history and he was referred by his primary care physician for FMTVDM/BEST imaging, which was performed via protocol $[11,12]$.

The results revealed a well-localized mass near the nipple of the left breast with a FMTVDM/BEST measure- 
ment of 310 consistent with breast cancer. The excision biopsy with clean margins confirmed the cancer Figure 2.

\section{Discussion}

Research presented at the 2018 European Society for Medical Oncology (ESMO) meetings in October of 2018 revealed an increased incidence in male breast cancer of $1.9 \%$ per year between 2000 and 2015 . The increased incidence was associated with a median age of 68.1 years, with $66.3 \%$ of the cases in the left breast.

Recommendations from the ESMO conference was for men to be treated with the same treatment modalities as women; however, diagnostic methods for finding the breast cancer are limited. FMTVDM/BEST imaging does not require breast tissue for compression as mammography does. Measurement of RBFDs and metabolism of male breast tissue is equally applicable in men as women and provides a diagnostic tool for the evaluation of men as well as women.

\section{References}

1. Fleming RM, Fleming MR, Dooley WC, Sheikh A, McKusick A, et al. (2018) FMTVDM-FHRWW \& BEST the first true "Quantitative" nuclear imaging protocols with proprietary equations following The Fleming Method (TFM) for nuclear scintillation equipment quantitative standardization. Biomed J Sci \& Tech Res 4: 1-4.

2. Fleming RM, Fleming MR, McKusick $A$, Chaudhuri $T$ (2018) FMTVDM-TFMCO: True quantification requires standardization of the tool being used to measure, with a known, unchanging standard to produce accurate, consistent and reproducible quantified measurements. J Nucl Card.

3. Fleming RM, Fleming MR, McKusick A, Chaudhuri TK, Dooley WC, et al. (2018) FMTVDMCP stress-first/stressonly imaging is here! But first we need to clarify the use of what (1) Stress, (2) Rest, (3) Redistribution and (4) Quantification, really mean. J Nucl Med Radiat Ther 9: 5.

4. Fleming RM, Fleming MR, McKusick A, Chaudhuri TK (2018) Semi-quantification limitations: FMTVDMCP demonstrates quantified tumor response to treatment with both regional blood flow and metabolic changes. J Nucl Med 59: 1643-1644.

5. Fleming RM, Fleming MR, McKusick A, Chaudhuri TK (2018) FMTVDMCP Nuclear Imaging Artificial (AI) Intelligence but fires we need to clarify the use of (1) Stress, (2) Rest, (3) Redistribution and (4) Quantification. Biomed J Sci \& Tech Res 7: 1-4.

6. Fleming RM, Fleming MR, McKusick A, Chaudhuri TK (2018) Virtual quantification is not True quantification. FMTVDM-TFMCP provides true quantification for SPECT and PET. Archives of Medicine 10.

7. Sheikh A (2018) Evolution of quantification in clinical nuclear medicine: A brief overview of salient uses and upcoming trends. J Nucl Med Radiat Ther 9: 4.

8. Fleming RM (2018) FMTVDMC® provides the first true SPECT and PET quantification and not virtual guesstimation produced by SUV and Extraction Fraction, yielding first accurate theranostic method. J Nucl Med Radiat Ther 9: 4.

9. Fleming RM, Fleming MR, Dooley WC, McKusick A, Chaudhuri T (2018) FMTVDMCO provides the first nuclear quantitative method for nuclear cardiology and introduces a new era for nuclear cardiology. J Nucl Card 25: 1453.

10. Fleming RM, Fleming MR, Chaudhuri TK, Dooley WC, McKusick A (2019) Letter to the editor: A response to Hruska's case study on molecular breast imaging and the need for true tissue quantification. Breast Cancer Res 21: 15.

11. The Fleming Method for Tissue and Vascular Differentiation and Metabolism (FMTVDM) using same state single or sequential quantification comparisons. Patent Number 9566037.

12. (2018) European Society for Medical Oncology (ESMO) 2018 Congress. 